\title{
Clinical-Surgical Correction
}

\author{
Case 2/2003 -Pediatrics Cardiac Surgery Service - Hospital de Base, \\ State Medicine School of São José do Rio Preto
}

Ulisses Alexandre CROTI e Domingo Marcolino BRAILE

\section{CLINICALDATA}

A full-term male white newborn baby presented with cyanotic crises on crying and breast-feeding on his the first day of life. Peripheral oxygen saturation was $65 \%$. The baby had a good general state, rosy complexion, he was hydrated, icteric and had tachydyspnea. Rhythmic, single second noise, hyperphonetic at the left sternal edge with a continuous murmur of $++/ 6$ at high right sternal edge. The lungs had vesicular murmur present and symmetrical without adventitious noise. The liver was positioned on the right costal edge and the spleen was not palpable. The peripheral pulses were present and symmetrical. The systemic arterial pressure was without difference at the four limbs. Infusion of prostaglandin E1 was initiated with improvement of the oxygen saturation at $87 \%$.

\section{ELECTROCARDIOGRAM}

The atrial rhythm alternated from the electric axis of the $\mathrm{P}$ wave at 145 beats/minute to the electric axis of the QRS complex $+120^{\circ}$. The $\mathrm{P}$ wave peaked at $\mathrm{V} 1, \mathrm{~V} 2$ and $\mathrm{V} 3$ and the pure and broad $\mathrm{R}$ wave at $\mathrm{V} 1$, suggesting right atrial and ventricular overload.

\section{RADIOGRAM}

The liver was meso-positioned suggesting situs ambiguous. The cardiothoracic index was 0.58 . Pulmonary

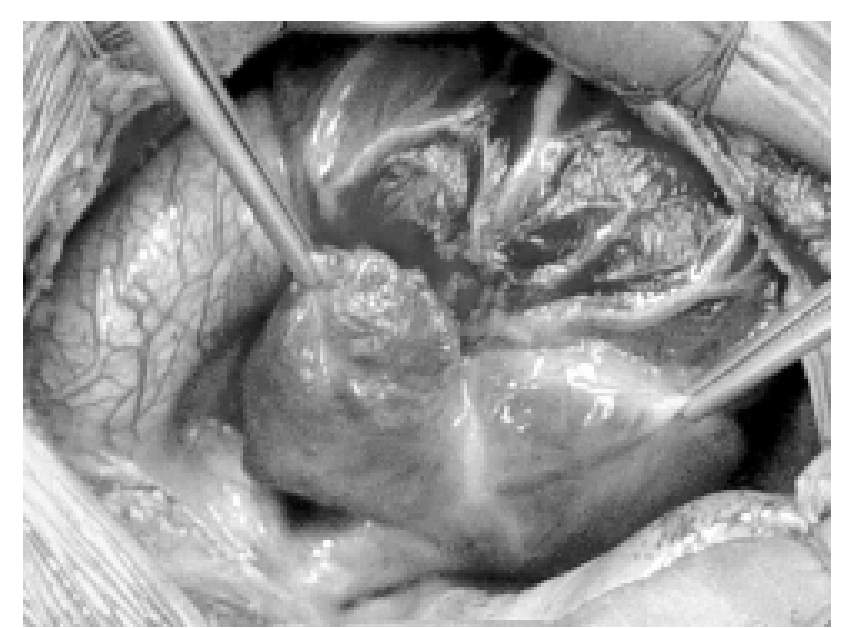

Fig. 1 - Intra-operative aspect demonstrating the position of the two atria (right atrial isomerism)

parenchyma was present with a slight increase of the vascular system.

\section{ECHOCARDIOGRAM}

Situs ambiguous at mesocardia, concordant veno-atrial connection, an atrioventricular connection with single atrioventricular valve, ventriculo-arterial connection with single aortic outflow tract from hypoplastic antero-superior

Correspondence address: Ulisses Alexandre Croti

Hospital de Base - FAMERP - Av. Brigadeiro Faria Lima, 5416 CEP 15090-000 - São José do Rio Preto - São Paulo

Article received on October, 2003 E-mail: uacroti@cardiol.b 
right ventricle were all evidenced. An ostium secundumtype interatrial connection of $4 \mathrm{~mm}$ and an ostium primum of $6 \mathrm{~mm}$ were seen, as was a copious interventricular connection of $9 \mathrm{~mm}$. The arterial canal was $2 \mathrm{~mm}$. Other findings included a single left-type ventricle, atresia of the pulmonary valve and branch and the presence of collateral systemicpulmonary circulation originating from the descending aorta.

\section{DIFFERENTIAL DIAGNOSIS}

Pulmonary atresia, double outflow tract of the right ventricle, unbalanced atrioventricular septum defect, anomalous drainage of the pulmonary veins and transposition of the great arteries should all be considered.

\section{DIAGNOSIS}

A cineangiocardiographic study complemented the diagnostic investigation demonstrating the presence of a patent left superior vena cava, right atrial isomerism, single left-type ventricle with single aortic outflow tract from the rudimentary chamber and a ostium secundum-type interatrial connection. Also a copious interventricular connection, aorta in dextroposition, patent arterial canal supplying hypoplastic pulmonary arteries and collateral systemicpulmonary circulation to both lungs were seen.

\section{SURGERY}

The cineangiocardiographic study was fundamental for the planning of the surgery, as it was a complex heart disease. The surgery was performed on the 25th day of life. In the presence of a long and twisting arterial canal supplying pulmonary arteries positioned in unusual positions, the choice of surgery was sternotomy and the modified BlalockTaussig operation with the insertion of a $3.5-\mathrm{mm}$ polytetrafluoroethylene tube from the brachiocephalic branch to the left pulmonary artery. Cardiopulmonary bypass was not employed. The arterial canal was not ligated with the intention of allowing a greater flow for the supplement and development of the pulmonary arteries. In the post-operative period, as he presented with right atrial isomerism and asplenia (confirmed by ultrasonography), he evolved with bacterial and fungal infections, which were appropriately treated and the patient was released from hospital on the 44th post-operative day. In the late evolution, rigorous care in relation to infections and out-patient followup visits are crucial to determine the best moment for the next cineangiocardiographic study and new intervention, at which a univentricular correction should be considered. 